\title{
The 1968 Antarctic Italian CAI-CNR mission: a story map to rediscover an almost unknown geographical exploration
}

\author{
Giovanni Mauro $^{\mathrm{a}, *}$, Alessia Glielmi ${ }^{\mathrm{b}}$ \\ ${ }^{a}$ University of Campania "Luigi Vanvitelli”-giovanni.mauro@unicampania.it \\ ${ }^{b}$ Consiglio Nazionale delle Ricerche (CNR) - alessia.glielmi@cnr.it \\ * Corresponding author
}

Keywords: Italian Antarctic mission, Wright Valley, Story map, Geographical exploration

\begin{abstract}
:
Even today, at the dawn of a new millennium, North and South Pole remain largely unknown areas. As part of the geographical explorations of the New Zealand Antarctic Research Programme in Victoria Land (a region of Antarctica located south of New Zealand), more than fifty years ago the Club Alpino Italiano (CAI) and the Consiglio Nazionale delle Ricerche (CNR) planned and economically supported the first Italian expedition to discover Antarctica. Between 1968 and 1969 a group of six people, three young researchers of CNR and University and three experienced alpinist, left Italy to the South Pole. They were divided into three teams of two people each: the first had to reach the American station of Mc Murdo on Ross Island by ship from Christchurch, in New Zealand; the other two had to explore the Wright Valley. This basin is located in the centre of the three large McMurdo Dry Valleys in the Transantarctic Mountains, west of the McMurdo Channel (approximately $77^{\circ} 30^{\prime} \mathrm{S}$ and $161^{\circ} 40^{\prime} \mathrm{E}$ ).
\end{abstract}

In November 1968 Marcello Manzoni (CNR geologist) and Ignazio Piussi (CAI alpinist) were the first two explorers of this mission who reached the scientific research station of Base Scott. Later they moved on Vanda Station, a nearby research base from where they began their exploration on December 15, 1968. Their journey on foot through the Wright Valley lasted 23 days. They covered about $240 \mathrm{~km}$ along a circular path (fig.1), sometimes facing extreme weather conditions. During their trip, they settled nine temporary base camps and they made eight first ascents including Mount St. Pauls (2300 m.), Round (2410 m.), Fleming (2250 m.) and Shapeless (2739 m.). They collected several geological samples; their scientific observations are still important for the definition of the granite outcrops of the upper Olympus Range and the stratigraphy of the Paleozoic-Mesozoic Beacon series. Their notes are collected in two different travel diaries: Manzoni wrote down personal impressions and scientific remarks, while Piussi recorded his own mountaineering exploits. This is one of the last geographical expeditions carried out before the advent of technological tools: today smartphone or GPS are part of our daily lives, but only a few decades ago their availability was not so obvious. At the end of 60's, it was unthinkable carrying heavy equipment, such as a 'simple' radio transmitter, on a mission on foot for several kilometres. Therefore, during their mission between the Antarctic valleys, the researchers were almost as isolated as the early navigators or ancient explorers.

Fifty years after this event, the CNR decided to rediscover this almost unknown story. Main data sources are the historical archive of CNR and the archives or documents of the protagonists of that project (i.e., Archivio Carlo Stocchino, documents of Marcello Manzoni, ancient reviews of CNR etc.). The data source about this mission is quite heterogeneous (i.e., traditional documents, pictures, historical scientific instruments, etc.), making archival research work rather complex. Very often selected material can be associated with a well-defined geographical location, so we decided to create a story map. Telling stories through maps is nothing new: as highlighted by Kersky (2015, p. 16), maps "provide a large amount of detail in a small amount of space" and their storytelling "began with describing explored lands in detail against terra incognita". However, current webGIS present somewhat of a revolution in cartography: through this tool we can include a lot of information on the map, so we can recover the plural meaning of the territory (Casti, 2018). As is well known, the world leader in the GIS market (ESRI) offers a good opportunity in this area: ESRI Story Maps, a specific product of web mapping applications working within the ArcGIS online platform. It combines different web templates with narrative text and multimedia content (photos, video, and audio capabilities), so that the expert users can easily create interactive web maps.

Based on the several information acquired from the CNR (also including an interview with one of the two protagonists, Marcello Manzoni), we mapped in detail the path of the Antarctic exploration of Manzoni and Piussi (fig.1). We also defined the location of the nine base camps, highlighting the position of the mountain peaks climbed during the mission. 
The user can achieve more information by selecting points or the line of the path: thus, he can find out the length of each section of the trail as well as view several old photos of this 'little' feat (fig.2). Throughout the creation of a story with georeferenced data, people would learn more about different territory-related aspects: having an overall and accurate location of this mission the user can have, for instance, detailed information about the Antarctic landscape geomorphology.

The opportunity to meet one of the two protagonists of this story, Marcello Manzoni, was one more reason to bring back the memory of such a daring mission, even to the youngest. We hope that the interactive ESRI Story Map will also make it known to a large audience. The storymap is available at:

https://www.arcgis.com/apps/MapJournal/index.html?appid=189ae8d6c7ce4bcc842e0dfde07a749c

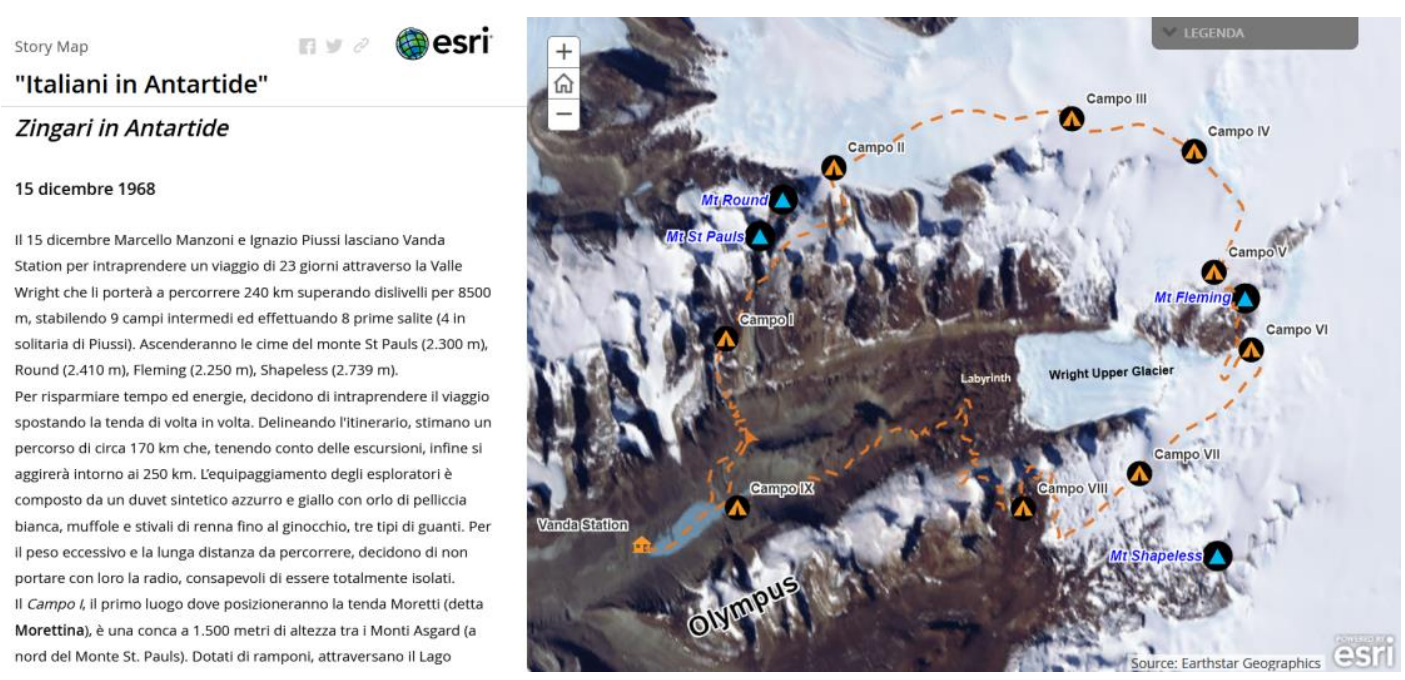

Figure 1. The path of the Manzoni and Piussi’s geographical exploration.

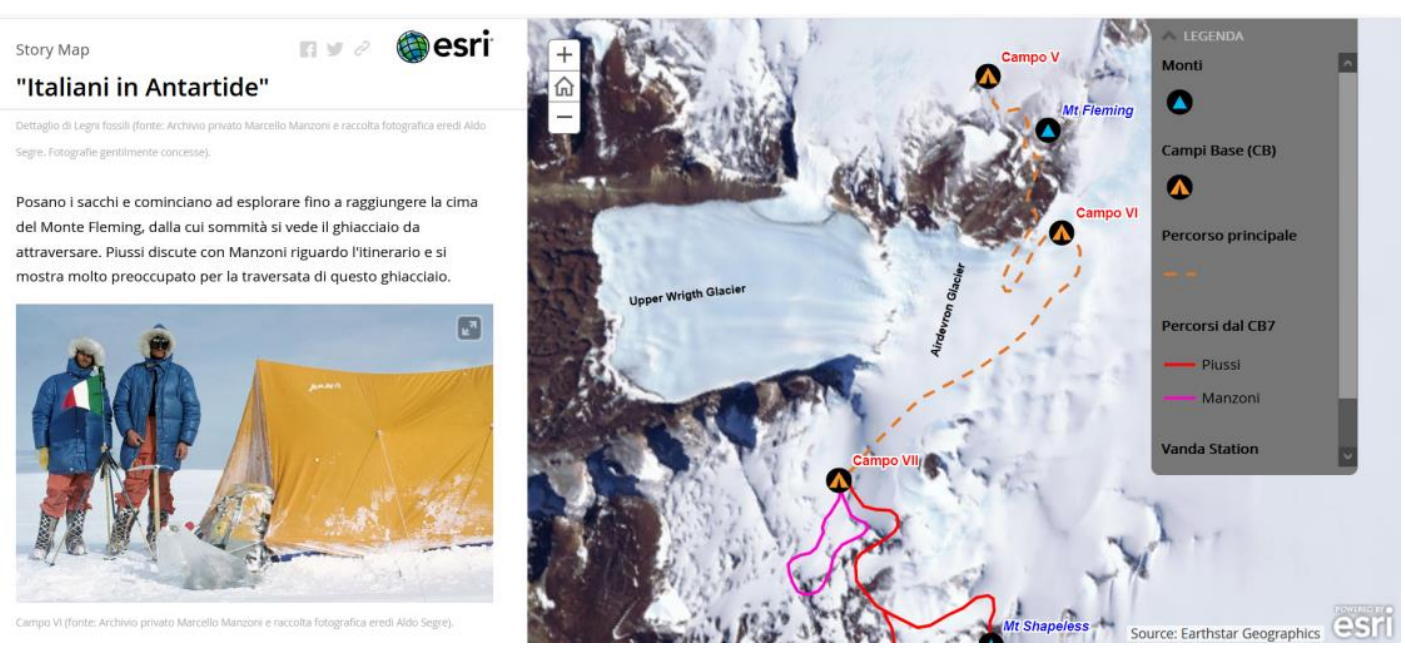

Figure 2. An example of the detailed information about a section of the trail.

\section{Acknowledgements}

We acknowledge Marcello Manzoni for supporting this research by providing its personal documentation.

\section{References}

Casti, E., 2018. Cartografia Critica, dal Topos alla Chora. Guerini e Associati, Milano.

Kerski, J.J., 2015. Geo-awareness, geo-enablement, geotechnologies, citizen science, and storytelling: Geographyon the world stage. Geography Compass, Vol. 9, n. 1, 14-26.

Manzoni, M., 2012. Zingari in Antartide. Alpine Studio, Lecco). 